\title{
Corrigendum: Quantifying the Beauty of Words: A Neurocognitive Poetics Perspective
}

\author{
Arthur M. Jacobs ${ }^{1,2,3 *}$ \\ ${ }^{1}$ Department of Experimental and Neurocognitive Psychology, Freie Universität Berlin, Berlin, Germany, ${ }^{2}$ Dahlem Institute for \\ Neuroimaging of Emotion, Berlin, Germany, ${ }^{3}$ Center for Cognitive Neuroscience Berlin, Berlin, Germany
}

Keywords: neurocognitive poetics, quantitative narrative analysis, machine learning, digital humanities, neuroaesthetics, computational stylistics, literary reading, decision trees

\section{A corrigendum on}

Quantifying the Beauty of Words: A Neurocognitive Poetics Perspective

by Jacobs, A. M. (2017). Front. Hum. Neurosci. 11:622. doi: 10.3389/fnhum.2017.00622

In the original article, Equation (1) in Appendix B in Data Sheet 1 contains an error. The correct equation is:

(1) mean[GNsim(word, label_1pos) $+\ldots+$ GNsim(word, label_Npos) $]-\operatorname{mean}[\mathrm{GNsim}$ (word, label_1neg) + ... + GNsim(word, label_Nneg)]

where GNsim is the so-called Lin similarity (Lin, 1998) defining semantic relatedness via a formula derived from information theory. This measure is sometimes called a universal semantic similarity measure as it is supposed to be application-, domain-, and resource independent (cf. Budanitsky and Hirst, 2006).

label_1pos and label_1neg/label_Npos and label_Nneg are the first and last terms, respectively, in either the valence or AP lists given in S2 and S3 of the supplementary materials,

\section{OPEN ACCESS}

Edited and reviewed by: Xiaolin Zhou,

Peking University, China

${ }^{*}$ Correspondence:

Arthur M. Jacobs ajacobs@zedat.fu-berlin.de

Received: 03 January 2018 Accepted: 11 January 2018 Published: 30 January 2018

Citation:

Jacobs AM (2018) Corrigendum: Quantifying the Beauty of Words: A Neurocognitive Poetics Perspective.

Front. Hum. Neurosci. 12:12

doi: 10.3389/fnhum.2018.00012 i.e., BEFRIEDIGUNG (satisfaction), ANGST (fear), or VERGNÜGEN (have fun), TRAUERN (mourn), and ANMUT (grace), WONNE (delight), or ABSCHEU (abomination), ZUMUTUNG (impertinence).

The original file Data Sheet 1 in the Supplementary Material has been updated.

\section{REFERENCES}

Budanitsky, A., and Hirst, G. (2006). Evaluating wordnet-based measures of lexical semantic relatedness. Comput. Linguist. 32, 13-47. doi: 10.1162/coli.2006.32.1.13

Lin, D. (1998). "An information-theoretic definition of similarity," in Proceedings of the Fifteenth International Conference on Machine Learning (ICML'98) (Madison, WI), 296-304.

Conflict of Interest Statement: The author declares that the research was conducted in the absence of any commercial or financial relationships that could be construed as a potential conflict of interest.

Copyright ( $\odot 2018$ Jacobs. This is an open-access article distributed under the terms of the Creative Commons Attribution License (CC BY). The use, distribution or reproduction in other forums is permitted, provided the original author(s) and the copyright owner are credited and that the original publication in this journal is cited, in accordance with accepted academic practice. No use, distribution or reproduction is permitted which does not comply with these terms. 